\title{
Chapter 3 \\ Evaluating Microplastic Experimental Design and Exposure Studies in Aquatic Organisms
}

\author{
Puspa L. Adhikari, Wokil Bam, Pamela L. Campbell, Francois Oberhaensli, \\ Marc Metian, Marc Besson, Hugo Jacob, and Peter W. Swarzenski
}

\begin{abstract}
Environmental microplastic particles (MPs) represent a potential threat to many aquatic animals, and experimental exposure studies, when done well, offer a quantitative approach to assess this stress systematically and reliably. While the scientific literature on MP studies in aquatic environments is rapidly growing, there is still much to learn, and this chapter presents a brief overview of some of the successful methods and pitfalls in experimental MP exposure studies. A short overview of some experimental design types and recommendations are also presented. A proper experimental exposure study will yield useful information on MP-organism impacts and must include the following: a comprehensive MP characterization (e.g., density, buoyancy, type, nature, size, shape, concentration, color, degree of weathering/biofilm formation, an assessment of co-contaminant/surfactant toxicity and behavior, an understanding exposure modes, dose and duration, and the type and life stage of the target species). Finally, more conventional experimental
\end{abstract}

\footnotetext{
P. L. Adhikari

Department of Marine and Earth Sciences, The Water School, Florida Gulf Coast University, Fort Myers, FL, USA

e-mail:padhikari@fgcu.edu

W. Bam

International Atomic Energy Agency- Environment Laboratories, Principality of Monaco, Monaco

Department of Oceanography and Coastal Sciences, Louisiana State University,

Baton Rouge, LA, USA

e-mail: bamwokil1@gmail.com; wbam1@1su.edu

P. L. Campbell

US Geological Survey, Pacific Coastal and Marine Science Center, Santa Cruz, CA, USA

F. Oberhaensli · M. Metian · M. Besson · H. Jacob · P. W. Swarzenski $(\bowtie)$

International Atomic Energy Agency- Environment Laboratories,

Principality of Monaco, Monaco

e-mail: f.r.oberhaensli@iaea.org; m.metian@iaea.org; marc.besson@ens-lyon.org;

hjacob2012@my.fit.edu; p.swarzenski@iaea.org
}

(C) The Author(s) 2022

M. S. Bank (ed.), Microplastic in the Environment: Pattern and Process,

Environmental Contamination Remediation and Management,

https://doi.org/10.1007/978-3-030-78627-4_3 
considerations, such as time, costs, and access to clean water, specialized instrumentation, and use of appropriate controls, replicate, and robust statistical analyses are also vital. This short review is intended as a necessary first step towards standardization of experimental MP exposure protocols so one can more reliably assess the transport and fate of MP in the aquatic environment as well as their potential impacts on aquatic organisms.

\subsection{Introduction}

Environmental plastic pollution is a ubiquitous phenomenon, affecting even the most remote environments on Earth, such as the Himalayas, the Arctic, and even the deepest marine trenches (Bergmann et al. 2017; Chiba et al. 2018). In addition to visible, macro-sized plastic litter that adversely may affect megafauna, there is another component of aquatic plastic pollution that remains harder to constrain, the microplastic particles (MP) (GESAMP 2015). MP has been conventionally defined as plastic particles less than $5 \mathrm{~mm}$ in size (Hidalgo-Ruz et al. 2012) and is either manufactured (primary MP) or the result of fragmentation and weathering of larger plastics (secondary MP). Some of the principal sources of MP in the aquatic environment are from rivers, wastewater treatment plants, atmospheric deposition (e.g., municipal dust), and some marine activities such as fishing and shipping (Cole et al. 2011).

It has been reported that more than 200 marine animal species have already been exposed to MP during some phase of their life cycles (Gall and Thompson 2015), either through direct ingestion or by trophic transfer of plastic-laden food (Lusher et al. 2017; Rochman 2015; Au et al. 2017; Auta et al. 2017; Paul-Pont et al. 2018; Botterell et al. 2019; Nelms et al. 2019). While the ubiquitous nature of MP pollution is an obvious potential threat to many aquatic organisms, we still lack a fundamental understanding of its impacts on biological systems (de Sá et al. 2018; Burns and Boxall 2018; Connors et al. 2017; Bucci et al. 2020). Carefully designed experimental exposure studies will enhance our understanding of the effects and underlying mechanisms of MP toxicity towards aquatic organisms. Such information can then guide policy decisions to strengthen and protect coastal and marine ecosystems.

\subsection{MP Parameters}

To design and conduct a meaningful MP exposure experiment using aquatic animals, the following parameters must be considered: MP type, chemical form, degree of weathering (or not), size, shape, concentration, color, density, presence of additives, sorbed chemical co-contaminants, exposure pathway and duration, target organism, and life stage (Fig. 3.1). 


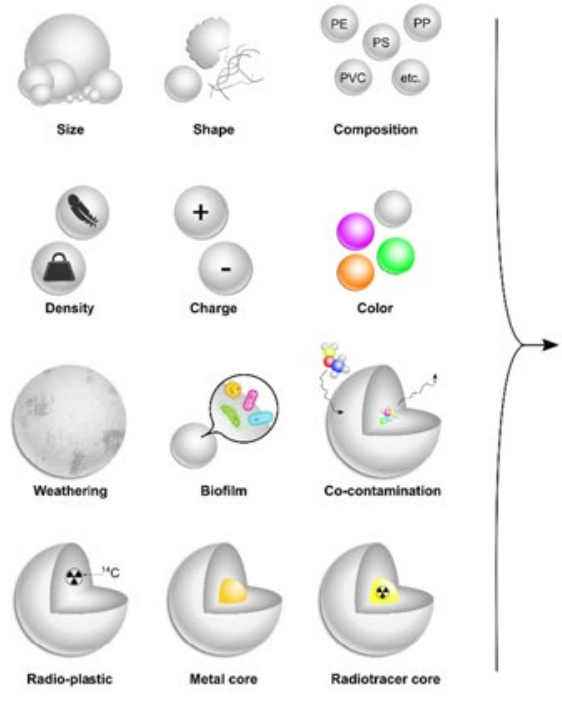

MP characteristics
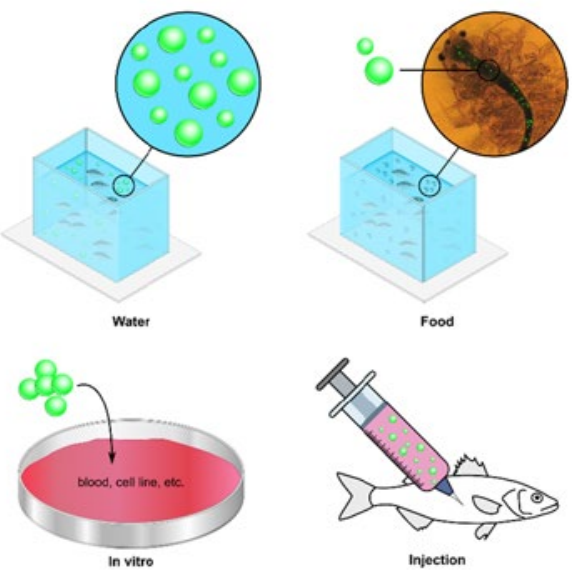

Injection

Fig. 3.1 An overview of the characterization of microplastic particles and their potential experimental exposure pathways (food and water) to aquatic organisms

\subsubsection{Chemical and Physical Character of MP}

In natural aquatic environments, MP are found as complex mixtures with different buoyancies, surface charge, color, composition (e.g., polymer type, presence of adsorbed contaminants and/or chemical additives, presence of biofilm and microorganisms), densities, shapes, and sizes. While some MP characteristics are quite easy to define and control, most require specific considerations. The following section discusses MP characteristics.

There are six plastic polymers that are most widely produced and thus observed in nature: polypropylene (PP), polyethylene (PE) that can occur both as high- and low-density polyethylene (HDPE, LDPE), polyvinyl chloride (PVC), polyurethane (PUR), polyethylene terephthalate (PET), and polystyrene (PS) (Browne et al. 2010; Karapanagioti et al. 2011; Vianello et al. 2013; Isobe et al. 2014; Enders et al. 2015; Frère et al. 2017). Among them, PE, PP, PS, and PET have been found to be the most abundant MP in the marine environment, followed by PVC (Rezania et al. 2018). PS is usually easiest to obtain and thus most widely used in laboratory exposure experiments. For MP fish exposure studies, PE is most utilized, followed by PS and PVC (Phuong et al. 2016; Botterell et al. 2019; Jacob et al. 2020).

MP can also exist in many shapes, such as spheres/beads, pellets, granules, fibers, films, fragments, and foams (Free et al. 2014; Karami 2017). While spheres are most often indicative of a primary MP, fragmentation and weathering will produce secondary MP that can irregularly shape spheres and fibers, films, fragments, 
and foams (Thompson 2015; Napper and Thompson 2016). Frydkjaer et al. (2017) found that irregular MP fragments were egested at a slower rate than spherical beads in experimental studies using Daphnia magna. The shape of a MP is thus an important factor in determining its effects in aquatic organisms (Bucci et al. 2020).

A wide range of MP size classes have been used in experimental exposure studies (Mattsson et al. 2015; Galloway et al. 2017; Ter Halle et al. 2017). According to some studies, the bioavailability and toxicity of MP can be highly size-dependent (Koelmans et al. 2020), with smaller particles generally exhibiting higher toxicity (Betts 2008, Jeong et al. 2016; Wright et al. 2013b; Bucci et al. 2020; Riberio et al. 2019; Wang et al. 2019) due to an increase in bioavailability and potential for translocation across the cell membrane (Browne et al. 2008). Physical blockage in the digestive tract has also been observed with certain MP size classes (Anbumani and Kakkar 2018). Currently, the selection of MP size for exposure experiments is often based on what is commercially available.

MP color can also vary widely, ranging from brightly colored to opaque and clear particles (Shaw and Day 1994; Su et al. 2016; Peters et al. 2017; Wang et al. 2017; Rezania et al. 2018; Zhang et al. 2018). Weathering will fade the original color into a secondary, usually less bright color (Chen et al. 2019). Importantly, the color of some MP may resemble natural food such as phytoplankton, which can affect ingestion rates and/or biological impacts to higher-trophic aquatic organisms (Wright et al. 2013).

The particle surface charge of MP is also an important characteristic that is affected by the ionic strength of natural waters. The shift from freshwater to seawater can dramatically change the aggregation properties and surface charge of particles, including MP. Generally, the physicochemical characterization of MP and its weathering will determine the efficiency of interactions with other particles and/or associated contaminants. The role of the MP surface charge on the toxicity for aquatic organisms is still not well understood (Paul-Pont et al. 2018). However, it has been suggested that the MP charge can play an important role in the transport, fate, and environmental effect of MP in the marine environment (Leslie 2012). The charge and surface properties of MP can play an important role in determining their effects to organisms, primarily due to their interaction with biological membranes (Cole et al. 2013; Rossi et al. 2013).

Polymer density will affect buoyancy and therefore bioavailability to target organisms. For example, high-density particles such as PET quickly sink, increasing bioavailability to benthic dwelling organisms, while pelagic filter/suspension feeders and planktonic feeders will be more readily exposed to low-density MP, such as PE (Wright et al. 2013). Continuous interaction of MP with other marine particles (i.e., ingestion/egestion, adsorption/desorption, aggregation/disaggregation, and biofouling) can also play a role in particle density (Cole et al. 2011, 2016; Kooi et al. 2017; Botterell et al. 2019). 


\subsubsection{Primary vs. Weathered MP}

Primary MP consists of various off-the-shelf polymers such as PP, PE, PVC, PUR, PET, and PS, which are most often not directly released into the aquatic environment. Once natural weathering processes occur (e.g., biofouling, organic coatings, or aggregation of MP with other marine particles), a change in the chemical and physical properties will alter the bioavailability and toxicity (White 2006; Cole et al. 2011, 2016; Kooi et al. 2017; Lambert et al. 2017; Botterell et al. 2019; Chen et al. 2019). MP introduced to natural waters for any length of time will develop an organic biofilm that will drastically impact the fate and behavior of MP and associated co-contaminants. The use of weathered MP in exposure studies more closely reflects the natural environment; thus, it is important to account for these weathering changes during an exposure experiment. It is worth noting that most studies to date typically use primary MP for their exposure experiments (Bråte et al. 2018; PaulPont et al. 2018; Botterell et al. 2019; Jacob et al. 2020) or have used experimentally weathered MP (e.g., by immersing plastic particles in water for a few weeks or introducing microorganisms to the MP).

\subsubsection{Microplastic Co-contaminants}

Microplastics are complex pollutants consisting of polymer blends, residual monomers, plastic additives, and diverse co-contaminants (Rochman 2015). A large number of chemicals and some persistent organic pollutants (POPs) are added to MP during manufacturing to increase polymerization properties and durability, and these can contribute up to $60 \%$ (e.g., PVC: Net et al. 2015) of the plastic polymer mass. The additives most commonly used in the manufacturing process are plasticizers, thermal stabilizers, pigments, lubricants, flame retardants, and acid scavengers. It has been reported that chemicals leached from primary MP pellets may cause more deleterious effects than the ingestion of the MP itself (Botterell et al. 2019). However, studies quantifying the effects of plastic additives on organisms are still rare (Browne et al. 2013; Rochman et al. 2013), and desorption processes of plastic-associated chemicals and their effects on aquatic biota including human health remain poorly understood. Expectedly, organisms with longer gut retention times (i.e., some fish) have the potential for increased exposure and therefore for increased toxicity of MP co-contaminants.

Due to their large surface-to-volume ratio and charged hydrophobic surfaces, MP provide an excellent sorption site to scavenge some particle-reactive, dissolved contaminants (e.g., PBTs, PBDEs, DDT, PAHs, and pharmaceuticals), trace metals (e.g., copper, zinc, lead), and other plastic additives (Teuten et al. 2007, 2009; Beckingham and Ghosh 2017; Ribeiro et al. 2019). Consequently, MP can also become a potential, albeit diffuse source for diverse co-contaminants (Koelmans et al. 2013, 2016; Avio et al. 2015; Brennecke et al. 2016; Nakashima et al. 2016; 
Alimi et al. 2018). It has been reported that the transport of HOCs (hydrophobic organic compounds) via MP is insignificant compared to their transport via natural particles (Burns and Boxall 2018; Riberio et al. 2019). Frydkjaer et al. (2017) found that $\mathrm{C}^{14}$-labeled phenanthrene (a three-ring PAH used as a tracer molecule) sorbed more to planktonic organisms than to PE MP in laboratory experiments. Moreover, little is known about the effects of these co-contaminants in the smaller size fractions of microplastics (Velzeboer et al. 2014).

As MP exist as a complex mixture of weathered polymers, additives, organic contaminants, and trace metals, it is very difficult to perform laboratory exposure experiments and differentiate the effects of each component (Galloway et al. 2017; Paul-Pont et al. 2018). Thus, there is a need to carefully characterize the sorbed chemicals and plastic additives when exposing organisms to these MP. As many studies are struggling to accurately characterize the MP itself (Costa et al. 2019), proper quantification of plastic-sorbed chemicals prior to and after an experimental exposure study is even more challenging. Analytically it is often difficult to differentiate the toxicological effects of co-contaminants vs. MP, especially at lower, environmentally relevant exposure concentrations.

\subsubsection{Application of Labelled Microplastics in Experimental Exposure Studies}

Some exposure experiments incorporate labeled MP with either fluorescent or embedded radioisotopes to obtain unique information on transport processes and bioaccumulation kinetics (Cole 2016; Lanctôt et al. 2018). Using fluorescencelabeled MP (i.e., Nile red dye) may enhance imaging (Cole et al. 2016), but one needs to be mindful as MP may also contain an inherent fluorescence which may compromise interpretation. Similarly, stable isotope-labeled MP tracers, using, for example, ${ }^{13}$ C-labelled MP (Berto et al. 2017), can yield important information on processes such as translocation, cycling, and biological impacts. Gamma- or betaray spectrometers are highly sensitive and not readily affected by typical interferences; thus, radiolabeled MP can be accurately quantified, even at trace levels, in complex environmental/biological samples and importantly, even in real time on live target organisms (Lanctôt et al. 2018). Radiolabeled MP can also be used to assess uptake and excretion routes, sorption/desorption kinetics, gut retention time, bioaccumulation, and trophic transfer. 


\subsection{How to Design a Meaningful Experimental Exposure Study?}

Anyone who has worked with MP in controlled exposure studies can attest to the abundant difficulties and challenges. MP introduced to an experimental aquarium will tend to accumulate at the water/air interface and will attach indiscriminately to any surface, including pumps, filters, the exterior of test organisms, and aquaria walls. Thus, MP contact with the target organism must often be facilitated. Experimentalists will almost always have to add a complexing agent/surfactant to the MP to better control the distribution of the MP. The synergistic toxicity of this organic surface-active agent should be carefully evaluated in the context of realistic exposure studies.

An ideal exposure experiment should thus be designed with careful consideration of the physical and chemical properties of MP, the sorbed co-contaminants and additives, as well as the MP concentration, the life cycle of the target organism, and mode and duration of exposure. Environmental parameters such as temperature, salinity, and the $\mathrm{pH}$ of ambient aquaria water should be carefully maintained and monitored as these too may have an important effect on the intrinsic chemical properties of the MP. Quantification of MP exposure and retention time, bioaccumulation rates, as well as the concentration of MP are critical for toxicokinetic studies to determine how and where MP is transported in an organism.

\subsubsection{Mode of Exposure}

Of the four conventional contaminant vectors (food, sediment, water, and parent-tooffspring transfer) commonly traced in experimental exposure studies on aquatic organisms, the two primary pathways of exposure for MP are water and food. For the water pathway, a known concentration of well-characterized MP can be directly introduced into the water column of a controlled aquarium; target organisms can be selected to match the nature of the introduced MP (i.e., bottom- vs. water columndwelling, life cycle). For the food pathway, target organisms can also be fed prey organisms contaminated with MP so that the target organism ingests the MP with the food (Figs. 3.2 and 3.3). This is a well-proven method to overcome some of the challenges of introducing a toxicant such as MP to living organisms.

\subsubsection{Concentration of MP for Exposure Studies}

The use of environmentally realistic concentrations of MP in exposure experiments is essential to obtain meaningful information for ecological risk assessments and resource protection (Huvet et al. 2016; Burton 2017; Karami 2017; Nyangoma de 


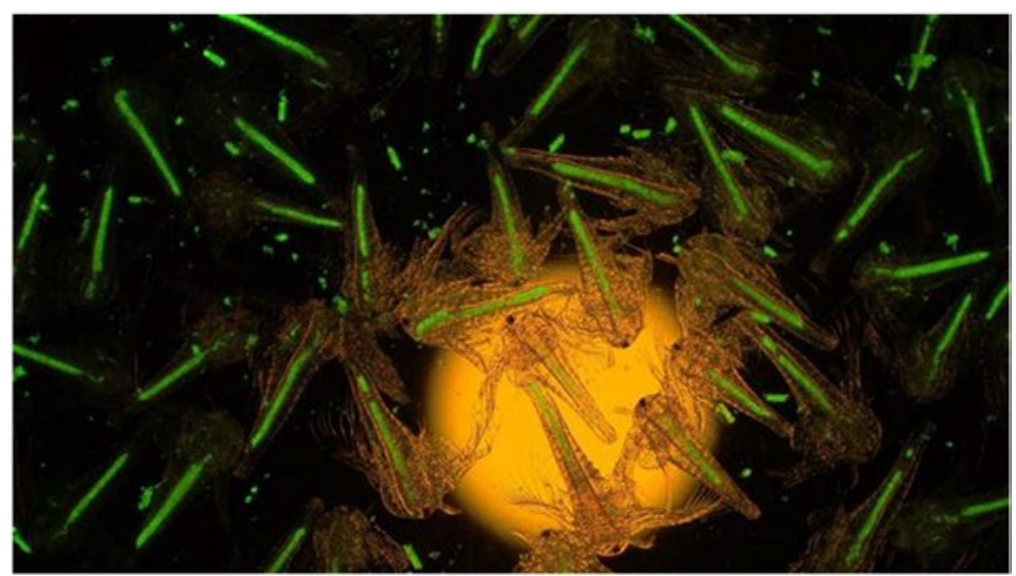

Fig. 3.2 Fluorescent microplastic particles line the stomach of artemia which are used as a microplastic-laden food for experimental exposure studies. (Photo credit: F. Oberhaensli, IAEA, Monaco)

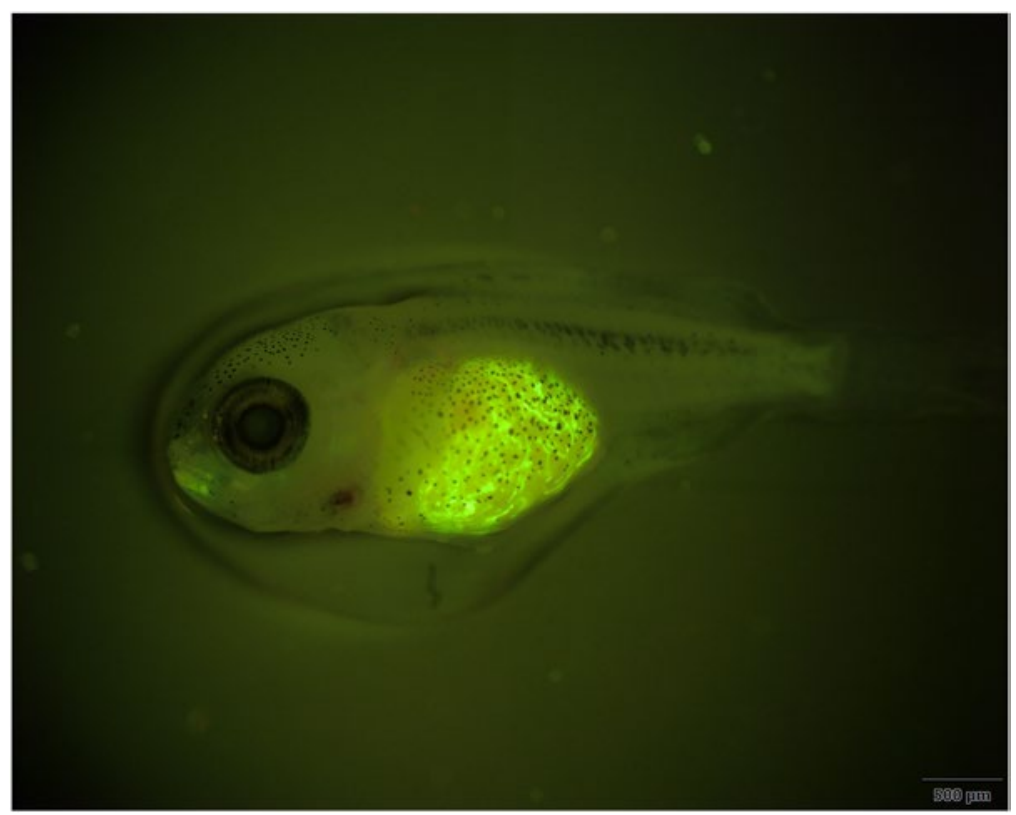

Fig. 3.3 Fluorescent microplastic particles line the stomach of a spiny chromis (Acanthochromis polyacanthus) fish. (Photo credit: M Besson, IAEA, Monaco) 
Ruijter et al. 2020; Koelmans et al. 2020). Currently, MP concentrations used in laboratory experiments are still often unrealistically elevated (Lenz et al. 2016; Rochman 2016), although we still have a lot to learn about MP abundance in nature (Brandon et al. 2019). Moreover, the deliberate use of elevated concentrations of MP in experiments can be a powerful approach to identify underlying mechanisms and processes that define MP transport and toxicity. The selection of environmentally realistic concentrations of MP for exposure studies is limited mainly by our analytical capabilities (Filella 2015; Lenz et al. 2016; Rochman 2016).

\subsubsection{Surfactants}

Natural and anthropogenic surfactants are ubiquitous in the aquatic environment, and their inherent toxicity to organisms is generally well-known. Due to the amphiphilic nature of surfactants, the surface tension of the water molecules is decreased which in turn increases the solubility of the HOCs. Surfactants are commonly used in MP exposure experiments to disperse the MP and increase bioavailability. The presence of a surfactant generally increases the formation of homo-agglomerates and promotes adhesion. Indeed, the added presence of a surfactant (MP + surfactant) may increase the toxicity of MP using a surfactant such as Triton X-100 or Tween 20 (Renzi et al. 2019), resulting in higher rates of immobilization. Smallersized MP dispersed throughout the water column by surfactants can produce mechanical damage such as impairment of filtration, affecting organism gut residence time, and translocation from the gut into tissues (Cole et al. 2013; Ma et al. 2016; Rehse et al. 2016). Using Daphnia magna as a test organism, Renzi et al. (2019) observed the formation of homo-agglomerates of MP, which can adhere to the surfaces of organisms, thereby reducing their motility and increasing energy consumption.

\subsubsection{Duration of Exposure}

Exposure duration of MP to a target organism is one of the most important parameters that can be easily controlled and one that will directly influence the outcome of an experiment. For example, the residence time and/or retention time of MP within an organism will play a major role in defining its toxicity and will also impact where the MP will eventually reside. The ingestion of MP also depends on the duration of exposure and frequency of feeding which contributes to tissue/organ accumulation and incorporation. Water changes in experimental aquaria must be completed carefully to not remove particles which would change the exposure concentration for the target organisms. Depending upon the duration of the exposure, MP and associated co-contaminants can be leached into the surrounding water column over time with possible additional consequences for aquatic organisms. For 
example, Pittura et al. (2018) suggested that it might take up to 28 days for a gradual shift in the toxicity of these MP from being mechanical to chemical in nature. Modeling time-series data of chemical toxicity in target organisms can help define acute vs. chronic effects. One of the advantages of using radiolabeled-MP with gamma-emitting radiotracers to study the fate and transport of MP in organisms is that experimental results can be obtained in real time using live target organisms at environmentally relevant concentrations. This permits a real-time assessment of experiment duration to reach an "equilibrium state," and subsequent experimental adjustments can be made to yield the desired outcome. There are few aquariumbased studies that expose test organisms with various concentrations of MP for both short- and long-term in order to determine both the acute and chronic effects of MP simultaneously (Critchell and Hoogenboom 2018; Wang et al. 2019).

\subsection{Recommendations}

Based on a literature overview (Table 3.1), there exists a need to better standardize MP exposure experiments to be able to provide meaningful and reproducible results. Working with MP in experimental aquaria is challenging, and one needs to keep track of many physicochemical parameters that will affect the experimental outcome, including the chemical form, shape, size and nature (primary vs. weathered, secondary), and the presence of a biofilm and/or co-contaminants (Burns and Boxall 2018; Bucci et al. 2020). Basic experimental exposure study considerations include the following: (i) at which MP concentrations should the experiment be designed, (ii) what are the reporting units, and (iii) what are the QA/QC parameters? An experiment designed with MP concentrations that are close to environmental levels will yield different information than if the experiments are conducted with elevated MP concentrations. Microplastic concentrations are typically expressed in milligram per liter for most toxicity studies although it may be more accurate to report as the number of particles per liter, since different MP types will have variable size ranges. It is therefore important to count the number of particles using a flow cytometer or other suitable counting methods. Surface charge and density considerations are also essential if the MP is to make proper contact with the selected target species (benthic vs. water column species).

Carefully designed experiments can provide useful insight to better understand MP impacts from cellular to organ, organism, and ecosystem levels. Exposure experiments should incorporate a carefully developed approach that includes physical, chemical, and biological factors that have a strong influence on both the target organism. Furthermore, conducting complementary field and/or laboratory-based studies could better define the scientific lacunae in representative sentinel species in single and combined exposure studies. Such complementary field data may provide useful information to better interpret laboratory-based studies to develop realistic assessments of organismal stress to MP (Anbumani and Kakkar 2018; Wright et al. 2019). 
Table 3.1 An overview of priorities and recommendations for experimental exposure studies of microplastics on aquatic organisms

\begin{tabular}{|c|c|}
\hline \multicolumn{2}{|c|}{ Priorities and recommendations } \\
\hline \multirow[t]{4}{*}{ Microplastics } & Use MP with varying physical and chemical properties \\
\hline & Evaluate the ecotoxicological effects of MP and associated co-contaminants \\
\hline & $\begin{array}{l}\text { Assess the bioaccumulation pathways of MP and co-contaminants through } \\
\text { aquatic food webs. }\end{array}$ \\
\hline & Use of primary and/or weathered MP to assess the specific organismal impacts \\
\hline \multirow{5}{*}{$\begin{array}{l}\text { Target } \\
\text { organisms }\end{array}$} & Use multispecies approach with emphasis on early life stages \\
\hline & $\begin{array}{l}\text { Investigate the impacts of MP on less-studied organisms (e.g., echinoderms, } \\
\text { cnidarians, and sponges) }\end{array}$ \\
\hline & Examine the link between MP, primary producers, and carbon flow \\
\hline & Assess biological effects on the community, population, and ecosystems \\
\hline & Investigate the transfer of MP to higher trophic species \\
\hline \multirow[t]{5}{*}{ Exposures } & Use high concentrations to study MP modes of action, kinetics, and processes \\
\hline & Assess the scavenging potential of natural particles versus MP \\
\hline & $\begin{array}{l}\text { Investigate potential dose rate or threshold responses by using gradient MP } \\
\text { concentrations and experiment durations }\end{array}$ \\
\hline & $\begin{array}{l}\text { Use environmentally relevant MP concentrations to assess potential ecological } \\
\text { impacts }\end{array}$ \\
\hline & $\begin{array}{l}\text { Study MP ingestion and trophic transfer in fish and compare the use of artificial } \\
\text { feed or live food }\end{array}$ \\
\hline \multirow[t]{5}{*}{ Methods } & $\begin{array}{l}\text { Develop specific biomonitoring indicators that can track organismal stress } \\
\text { including inflammation, intestinal dysbiosis, neurotoxicity and behavioral } \\
\text { change, and metabolic alterations }\end{array}$ \\
\hline & Develop and use a best practice guide for MP research \\
\hline & $\begin{array}{l}\text { Assess the impacts of MP on various biological functions, e.g., enzymatic, } \\
\text { genetic, histological, reproductive, developmental and physiological functions, } \\
\text { as well as immune and stress-related responses, cell signaling, energy } \\
\text { homeostasis }\end{array}$ \\
\hline & $\begin{array}{l}\text { Avoid external contamination with MP of experiments to determine accurate } \\
\text { impact by a regular monitoring of experimental conditions }\end{array}$ \\
\hline & $\begin{array}{l}\text { Study the effects of MP at different levels of biological organization (atomic, } \\
\text { molecular, cellular, tissue/organ, individual, community, trans-generational) }\end{array}$ \\
\hline
\end{tabular}

Previous studies have generally focused on MP effects on target organisms by treating MP as a single pollutant as opposed to a more realistic mixture of pollutants. There is thus the need to conduct experiments on MP and associated cocontaminant mixtures (Burns and Boxall 2018). Because we still have a lot to learn on proper characterization techniques for MP, special emphasis should be placed on the development and standardization of optimized analytical methods. The application of radiolabeled MP exposure experiments can provide better detection limits even at environmental or trace concentrations and can be an excellent method for elucidating the trophic transfer and movement of MP in live organisms.

The ideal experimental setup should be simple in design and should yield reproducible results using realistic MP concentrations, exposure routes, times, and target 
organisms. Depending on the specific research question, experimental MP exposure studies may first incorporate a simplified experimental design where one indicator species is exposed to a single type of MP. Subsequent studies may then build on these results and more complex experimental designs will yield more precise information on the organismal effects of MP. While the best laboratory exposure experiments currently address the effects of MP on target organisms under a set of environmental conditions, the next generation studies could address synergistic effects of mixed MP and associated co-contaminants on multiple species. This would be a logical extension of current state-of-the-art exposure experiments and would provide information that more closely resembles a natural aquatic ecosystem.

Acknowledgments PWS, MM, and FO of the IAEA are grateful for the support provided to its Environment Laboratories by the Government of the Principality of Monaco. This work was partly funded by generous contributions through the IAEA Peaceful Uses Initiative (PUI).

\section{References}

Alimi OS, Budarz JF, Hernandez LM, Tufenkji N (2018) Microplastics and nanoplastics in aquatic environments: aggregation, deposition, and enhanced contaminant transport. Environ Sci Technol 52(4):1704-1724. https://doi.org/10.1021/acs.est.7b05559

Anbumani S, Kakkar P (2018) Ecotoxicological effects of microplastics on biota: a review. Environ Sci Pollut Res 25(15):14373-14396. https://doi.org/10.1007/s11356-018-1999-x

Au SY, Lee CM, Weinstein JE, Hurk PVD, Klaine SJ (2017) Trophic transfer of microplastics in aquatic ecosystems: identifying critical research needs. Integr Environ Assess Manag 13(3):505-509. https://doi.org/10.1002/ieam.1907

Auta H, Emenike C, Fauziah S (2017) Distribution and importance of microplastics in the marine environment: a review of the sources, fate, effects, and potential solutions. Environ Int 102:165-176. https://doi.org/10.1016/j.envint.2017.02.013

Avio CG, Gorbi S, Milan M, Benedetti M, Fattorini D, Derrico G et al (2015) Pollutants bioavailability and toxicological risk from microplastics to marine mussels. Environ Pollut 198:211-222. https://doi.org/10.1016/j.envpol.2014.12.021

Beckingham B, Ghosh U (2017) Differential bioavailability of polychlorinated biphenyls associated with environmental particles: microplastic in comparison to wood, coal and biochar. Environ Pollut 220:150-158. https://doi.org/10.1016/j.envpol.2016.09.033

Bergmann M, Wirzberger V, Krumpen T, Lorenz C, Primpke S, Tekman MB, Gerdts G (2017) High quantities of microplastic in arctic deep-sea sediments from the HAUSGARTEN observatory. Environ Sci Technol 51(19):11000-11010. https://doi.org/10.1021/acs.est.7b03331

Berto D, Rampazzo F, Gion C, Noventa S, Ronchi F, Traldi U et al (2017) Preliminary study to characterize plastic polymers using elemental analyser/isotope ratio mass spectrometry (EA/ IRMS). Chemosphere 176:47-56. https://doi.org/10.1016/j.chemosphere.2017.02.090

Betts K (2008) Why small plastic particles may pose a big problem in the oceans. Environ Sci Technol 42(24):8995-8995. https://doi.org/10.1021/es802970v

Botterell ZL, Beaumont N, Dorrington T, Steinke M, Thompson RC, Lindeque PK (2019) Bioavailability and effects of microplastics on marine zooplankton: a review. Environ Pollut 245:98-110. https://doi.org/10.1016/j.envpol.2018.10.065

Brandon JA, Jones W, Ohman MD (2019) Multidecadal increase in plastic particles in coastal ocean sediments. Sci Adv 5(9). https://doi.org/10.1126/sciadv.aax0587 
Bråte ILN, Blázquez M, Brooks SJ, Thomas KV (2018) Weathering impacts the uptake of polyethylene microparticles from toothpaste in Mediterranean mussels (M. galloprovincialis). Sci Total Environ 626:1310-1318. https://doi.org/10.1016/j.scitotenv.2018.01.141

Brennecke D, Duarte B, Paiva F, Caçador I, Canning-Clode J (2016) Microplastics as vector for heavy metal contamination from the marine environment. Estuar Coast Shelf Sci 178:189-195. https://doi.org/10.1016/j.ecss.2015.12.003

Browne M, Dissanayake A, Galloway T, Lowe D, Thompson R (2008) Ingested microscopic plastic translocates to the circulatory system of the mussel, Mytilus edulis (L.). Environ Sci Technol 42:5026-5031

Browne MA, Galloway TS, Thompson RC (2010) Spatial patterns of plastic debris along estuarine shorelines. Environ Sci Technol 44(9):3404-3409. https://doi.org/10.1021/es903784e

Browne MA, Niven SJ, Galloway TS, Rowland SJ, Thompson RC (2013) Microplastic moves pollutants and additives to worms, reducing functions linked to health and biodiversity. Curr Biol 23(23):2388-2392. https://doi.org/10.1016/j.cub.2013.10.012

Bucci K, Tulio M, Rochman CM (2020) What is known and unknown about the effects of plastic pollution: a meta-analysis and systematic review. Ecol Appl 30(2). https://doi.org/10.1002/ eap.2044

Burns EE, Boxall AB (2018) Microplastics in the aquatic environment: evidence for or against adverse impacts and major knowledge gaps. Environ Toxicol Chem 37(11):2776-2796. https:// doi.org/10.1002/etc. 4268

Burton GA (2017) Stressor exposures determine risk: so, why do fellow scientists continue to focus on superficial microplastics risk? Environ Sci Technol 51(23):13515-13516. https://doi. org/10.1021/acs.est.7b05463

Chen Q, Zhang H, Allgeier A, Zhou Q, Ouellet JD, Crawford SE et al (2019) Marine microplastics bound dioxin-like chemicals: model explanation and risk assessment. J Hazard Mater 364:82-90. https://doi.org/10.1016/j.jhazmat.2018.10.032

Chiba S, Saito H, Fletcher R, Yogi T, Kayo M, Miyagi S et al (2018) Human footprint in the abyss: 30 year records of deep-sea plastic debris. Mar Policy 96:204-212. https://doi.org/10.1016/j. marpol.2018.03.022

Cole M (2016) A novel method for preparing microplastic fibers. Sci Rep 6(1). https://doi. org/10.1038/srep34519

Cole M, Lindeque P, Halsband C, Galloway TS (2011) Microplastics as contaminants in the marine environment: a review. Mar Pollut Bull 62(12):2588-2597. https://doi.org/10.1016/j. marpolbul.2011.09.025

Cole M, Lindeque P, Fileman E, Halsband C, Goodhead R, Moger J, Galloway TS (2013) Microplastic ingestion by zooplankton. Environ Sci Technol 47(12):6646-6655. https://doi. org/10.1021/es400663f

Cole M, Lindeque PK, Fileman E, Clark J, Lewis C, Halsband C, Galloway TS (2016) Microplastics alter the properties and sinking rates of zooplankton faecal pellets. Environ Sci Technol 50(6):3239-3246. https://doi.org/10.1021/acs.est.5b05905

Connors KA, Dyer SD, Belanger SE (2017) Advancing the quality of environmental microplastic research. Environ Toxicol Chem 36(7):1697-1703. https://doi.org/10.1002/etc.3829

Costa JPD, Reis V, Paço A, Costa M, Duarte AC, Rocha-Santos T (2019) Micro(nano)plastics analytical challenges towards risk evaluation. TrAC Trends Anal Chem 111:173-184. https:// doi.org/10.1016/j.trac.2018.12.013

Critchell K, Hoogenboom MO (2018) Effects of microplastic exposure on the body condition and behaviour of planktivorous reef fish (Acanthochromis polyacanthus). PLoS One 13(3). https:// doi.org/10.1371/journal.pone. 0193308

de Sá LC, Oliveira M, Ribeiro F, Rocha TL, Futter MN (2018) Studies of the effects of microplastics on aquatic organisms: what do we know and where should we focus our efforts in the future? Sci Total Environ 645:1029-1039. https://doi.org/10.1016/j.scitotenv.2018.07.207 
Enders K, Lenz R, Stedmon CA, Nielsen TG (2015) Abundance, size and polymer composition of marine microplastics $\geq 10 \mu \mathrm{m}$ in the Atlantic Ocean and their modelled vertical distribution. Mar Pollut Bull 100(1):70-81. https://doi.org/10.1016/j.marpolbul.2015.09.027

Filella M (2015) Questions of size and numbers in environmental research on microplastics: methodological and conceptual aspects. Environ Chem 12(5):527. https://doi.org/10.1071/en15012

Free CM, Jensen OP, Mason SA, Eriksen M, Williamson NJ, Boldgiv B (2014) High levels of microplastic pollution in a large, remote, mountain lake. Mar Pollut Bull 85(1):156-163. https://doi.org/10.1016/j.marpolbul.2014.06.001

Frère L, Paul-Pont I, Rinnert E, Petton S, Jaffré J, Bihannic I et al (2017) Influence of environmental and anthropogenic factors on the composition, concentration and spatial distribution of microplastics: a case study of the bay of Brest (Brittany, France). Environ Pollut 225:211-222. https://doi.org/10.1016/j.envpol.2017.03.023

Frydkjær CK, Iversen N, Roslev P (2017) Ingestion and egestion of microplastics by the cladoceran Daphnia magna: effects of regular and irregular shaped plastic and sorbed phenanthrene. Bull Environ Contam Toxicol 99(6):655-661

Gall S, Thompson R (2015) The impact of debris on marine life. Mar Pollut Bull 92(1-2):170-179. https://doi.org/10.1016/j.marpolbul.2014.12.041

Galloway TS, Cole M, Lewis C (2017) Interactions of microplastic debris throughout the marine ecosystem. Nat Ecol Evol 1(5). https://doi.org/10.1038/s41559-017-0116

GESAMP (2015) Sources, Fate and Effects of Microplastics in the marine Environment: A Global Assessment, Reports and Studies GESAMP. IMO/FAO/UNESCO-ioc/unido/wmo/ iaea/un/unep/undp Joint Group of Experts on the Scientific Aspects of Marine Environmental Protection. doi:https://doi.org/10.13140/RG.2.1.3803.7925

Hidalgo-Ruz V, Gutow L, Thompson RC, Thiel M (2012) Microplastics in the marine environment: a review of the methods used for identification and quantification. Environ Sci Technol 46(6):3060-3075. https://doi.org/10.1021/es2031505

Huvet A, Paul-Pont I, Fabioux C, Lambert C, Suquet M, Thomas Y et al (2016) Reply to Lenz et al.: quantifying the smallest microplastics is the challenge for a comprehensive view of their environmental impacts. Proc Natl Acad Sci 113(29). https://doi.org/10.1073/pnas.1607221113

Isobe A, Kubo K, Tamura Y, Kako SI, Nakashima E, Fujii N (2014) Selective transport of microplastics and mesoplastics by drifting in coastal waters. Mar Pollut Bull 89(1-2):324-330. https://doi.org/10.1016/j.marpolbul.2014.09.041

Jacob H, Besson M, Swarzenski PW, Lecchini D, Metian M (2020) Effects of virgin microand nanoplastics on fish: trends, meta-analysis, and perspectives. Environ Sci Technol 54(8):4733-4745. https://doi.org/10.1021/acs.est.9b05995

Jeong C-B, Won E-J, Kang H-M, Lee M-C, Hwang D-S, Hwang U-K et al (2016) Microplastic size-dependent toxicity, oxidative stress induction, and p-JNK and p-p38 activation in the monogonont rotifer (Brachionus koreanus). Environ Sci Technol 50(16):8849-8857. https:// doi.org/10.1021/acs.est.6b01441

Karami A (2017) Gaps in aquatic toxicological studies of microplastics. Chemosphere 184:841-848. https://doi.org/10.1016/j.chemosphere.2017.06.048

Karapanagioti H, Endo S, Ogata Y, Takada H (2011) Diffuse pollution by persistent organic pollutants as measured in plastic pellets sampled from various beaches in Greece. Mar Pollut Bull 62(2):312-317. https://doi.org/10.1016/j.marpolbul.2010.10.009

Koelmans AA, Redondo-Hasselerharm PE, Nor NHM, Kooi M (2020) Solving the non-alignment of methods and approaches used in microplastic research in order to consistently characterize risk. Environ Sci Technol. https://doi.org/10.1021/acs.est.0c02982

Koelmans AA, Besseling E, Wegner A, Foekema EM (2013) Plastic as a carrier of POPs to aquatic organisms: a model analysis. Environ Sci Technol 47(14):7812-7820. https://doi.org/10.1021/ es401169n

Koelmans AA, Bakir A, Burton GA, Janssen CR (2016) Microplastic as a vector for chemicals in the aquatic environment: critical review and model-supported reinterpretation of empirical studies. Environ Sci Technol 50(7):3315-3326. https://doi.org/10.1021/acs.est.5b06069 
Koelmans AA, Redondo-Hasselerharm PE, Mohamed Nor NH, Kooi M (2020) Solving the nonalignment of methods and approaches used in microplastic research to consistently characterize risk. Environ Sci Technol 54(19):12307-12315. https://doi.org/10.1021/acs.est.0c02982

Kooi M, Nes EHV, Scheffer M, Koelmans AA (2017) Ups and downs in the ocean: effects of biofouling on vertical transport of microplastics. Environ Sci Technol 51(14):7963-7971. https:// doi.org/10.1021/acs.est.6b04702

Lambert S, Scherer C, Wagner M (2017) Ecotoxicity testing of microplastics: considering the heterogeneity of physicochemical properties. Integr Environ Assess Manag 13(3):470-475. https://doi.org/10.1002/ieam.1901

Lanctôt CM, Al-Sid-Cheikh M, Catarino AI, Cresswell T, Danis B, Karapanagioti HK et al (2018) Application of nuclear techniques to environmental plastics research. J Environ Radioact 192:368-375. https://doi.org/10.1016/j.jenvrad.2018.07.019

Lenz R, Enders K, Nielsen TG (2016) Microplastic exposure studies should be environmentally realistic. Proc Natl Acad Sci 113(29). https://doi.org/10.1073/pnas.1606615113

Leslie HA (2012) Microplastic in Noordzee Zwevend stof en Cosmetica. EindrapportageW-12/01, Institute for Environmental Studies, Amsterdam

Lusher AL, Welden NA, Sobral P, Cole M (2017) Sampling, isolating and identifying microplastics ingested by fish and invertebrates. Anal Methods 9(9):1346-1360. https://doi.org/10.1039/ c6ay02415g

Ma Y, Huang A, Cao S, Sun F, Wang L, Guo H, Ji R (2016) Effects of nanoplastics and microplastics on toxicity, bioaccumulation, and environmental fate of phenanthrene in fresh water. Environ Pollut 219:166-173. https://doi.org/10.1016/j.envpol.2016.10.061

Mattsson K, Hansson L-A, Cedervall T (2015) Nano-plastics in the aquatic environment. Environ Sci: Processes Impacts 17(10):1712-1721. https://doi.org/10.1039/c5em00227c

Nakashima E, Isobe A, Kako S, Itai T, Takahashi S, Guo X (2016) The potential of oceanic transport and onshore leaching of additive-derived lead by marine macro-plastic debris. Mar Pollut Bull 107(1):333-339. https://doi.org/10.1016/j.marpolbul.2016.03.038

Napper IE, Thompson RC (2016) Release of synthetic microplastic plastic fibres from domestic washing machines: effects of fabric type and washing conditions. Mar Pollut Bull 112(1-2):39-45. https://doi.org/10.1016/j.marpolbul.2016.09.025

Nelms SE, Barnett J, Brownlow A, Davison NJ, Deaville R, Galloway TS et al (2019) Microplastics in marine mammals stranded around the British coast: ubiquitous but transitory? Sci Rep 9(1). https://doi.org/10.1038/s41598-018-37428-3

Net S, Sempéré R, Delmont A, Paluselli A, Ouddane B (2015) Occurrence, fate, behavior and ecotoxicological state of phthalates in different environmental matrices. Environ Sci Technol 49(7):4019-4035. https://doi.org/10.1021/es505233b

Nyangoma de Ruijter V, Redondo-Hasselerharm PE, Gouin T, Koelmans AA (2020) Quality criteria for microplastic effect studies in the context of risk assessment: a critical review. Environ Sci Technol. https://doi.org/10.1021/acs.est.0c03057

Paul-Pont I, Tallec K, Gonzalez-Fernandez C, Lambert C, Vincent D, Mazurais D et al (2018) Constraints and priorities for conducting experimental exposures of marine organisms to microplastics. Front Mar Sci 5. https://doi.org/10.3389/fmars.2018.00252

Peters CA, Thomas PA, Rieper KB, Bratton SP (2017) Foraging preferences influence microplastic ingestion by six marine fish species from the Texas Gulf Coast. Mar Pollut Bull 124(1):82-88. https://doi.org/10.1016/j.marpolbul.2017.06.080

Phuong NN, Zalouk-Vergnoux A, Poirier L, Kamari A, Châtel A, Mouneyrac C, Lagarde F (2016) Is there any consistency between the microplastics found in the field and those used in laboratory experiments? Environ Pollut 211:111-123. https://doi.org/10.1016/j.envpol.2015.12.035

Pittura L, Avio CG, Giuliani ME, Derrico G, Keiter SH, Cormier B et al (2018) Microplastics as vehicles of environmental pahs to marine organisms: combined chemical and physical hazards to the mediterranean mussels, Mytilus galloprovincialis. Front Mar Sci 5. https://doi. org/10.3389/fmars.2018.00103 
Rehse S, Kloas W, Zarfl C (2016) Short-term exposure with high concentrations of pristine microplastic particles leads to immobilisation of Daphnia magna. Chemosphere 153:91-99. https:// doi.org/10.1016/j.chemosphere.2016.02.133

Renzi M, Grazioli E, Blašković A (2019) Effects of different microplastic types and surfactantmicroplastic mixtures under fasting and feeding conditions: a case study on Daphnia magna. Bull Environ Contam Toxicol 103(3):367-373. https://doi.org/10.1007/s00128-019-02678-y

Rezania S, Park J, Din MFM, Taib SM, Talaiekhozani A, Yadav KK, Kamyab H (2018) Microplastics pollution in different aquatic environments and biota: a review of recent studies. Mar Pollut Bull 133:191-208. https://doi.org/10.1016/j.marpolbul.2018.05.022

Ribeiro F, Obrien JW, Galloway T, Thomas KV (2019) Accumulation and fate of nano- and microplastics and associated contaminants in organisms. TrAC Trends Anal Chem 111:139-147. https://doi.org/10.1016/j.trac.2018.12.010

Rochman CM (2015) The complex mixture, fate and toxicity of chemicals associated with plastic debris in the marine environment. In: Marine anthropogenic litter. Springer, Cham, pp 117-140. https://doi.org/10.1007/978-3-319-16510-3_5

Rochman CM (2016) Ecologically relevant data are policy-relevant data. Science 352(6290):1172-1172. https://doi.org/10.1126/science.aaf8697

Rochman CM, Hoh E, Hentschel BT, Kaye S (2013) Long-term field measurement of sorption of organic contaminants to five types of plastic pellets: implications for plastic marine debris. Environ Sci Technol 47(3):1646-1654

Rossi G, Barnoud J, Monticelli L (2013) Polystyrene nanoparticles perturb lipid membranes. J Phys Chem Lett 5(1):241-246. https://doi.org/10.1021/jz402234c

Shaw DG, Day RH (1994) Colour- and form-dependent loss of plastic micro-debris from the North Pacific Ocean. Mar Pollut Bull 28(1):39-43. https://doi.org/10.1016/0025-326x(94)90184-8

Su L, Xue Y, Li L, Yang D, Kolandhasamy P, Li D, Shi H (2016) Microplastics in Taihu Lake, China. Environ Pollut 216:711-719. https://doi.org/10.1016/j.envpol.2016.06.036

Ter Halle A, Jeanneau LT, Martignac MT, Jardé ET, Pedrono BT, Brach LT, Gigault JT (2017) Nanoplastic in the North Atlantic subtropical gyre. Environ Sci Technol 51(23):13689-13697. https://doi.org/10.1021/acs.est.7b03667

Teuten EL, Rowland SJ, Galloway TS, Thompson RC (2007) Potential for plastics to transport hydrophobic contaminants. Environ Sci Technol 41(22):7759-7764. https://doi.org/10.1021/ es071737s

Teuten EL, Saquing JM, Knappe DRU, Barlaz MA, Jonsson S, Björn A et al (2009) Transport and release of chemicals from plastics to the environment and to wildlife. Philos Trans R Soc B Biol Sci 364(1526):2027-2045. https://doi.org/10.1098/rstb.2008.0284

Thompson RC (2015) Microplastics in the marine environment: sources, consequences and solutions. In: Marine anthropogenic litter. Springer, Cham, pp 185-200. https://doi. org/10.1007/978-3-319-16510-3_7

Velzeboer I, Kwadijk CJAF, Koelmans AA (2014) Strong sorption of PCBs to nanoplastics, microplastics, carbon nanotubes, and fullerenes. Environ Sci Technol 48(9):4869-4876. https://doi. org/10.1021/es405721v

Vianello A, Boldrin A, Guerriero P, Moschino V, Rella R, Sturaro A, Ros LD (2013) Microplastic particles in sediments of lagoon of Venice, Italy: first observations on occurrence, spatial patterns and identification. Estuar Coast Shelf Sci 130:54-61. https://doi.org/10.1016/j. ecss.2013.03.022

Wang W, Ndungu AW, Li Z, Wang J (2017) Microplastics pollution in inland freshwaters of China: a case study in urban surface waters of Wuhan, China. Sci Total Environ 575:1369-1374. https://doi.org/10.1016/j.scitotenv.2016.09.213

Wang W, Gao H, Jin S, Li R, Na G (2019) The ecotoxicological effects of microplastics on aquatic food web, from primary producer to human: a review. Ecotoxicol Environ Saf 173:110-117. https://doi.org/10.1016/j.ecoenv.2019.01.113

White JR (2006) Polymer ageing: physics, chemistry or engineering? Time to reflect. C R Chim 9(11-12):1396-1408. https://doi.org/10.1016/j.crci.2006.07.008 
Wright SL, Rowe D, Thompson RC, Galloway TS (2013) Microplastic ingestion decreases energy reserves in marine worms. Curr Biol 23(23). https://doi.org/10.1016/j.cub.2013.10.068

Wright SL, Thompson RC, Galloway TS (2013b) The physical impacts of microplastics on marine organisms: a review. Environ Pollut 178:483-492. https://doi.org/10.1016/j.envpol.2013.02.031

Wright SL, Levermore JM, Kelly FJ (2019) Raman spectral imaging for the detection of inhalable microplastics in ambient particulate matter samples. Environ Sci Technol 53(15):8947-8956. https://doi.org/10.1021/acs.est.8b06663

Zhang K, Shi H, Peng J, Wang Y, Xiong X, Wu C, Lam PK (2018) Microplastic pollution in Chinas inland water systems: a review of findings, methods, characteristics, effects, and management. Sci Total Environ 630:1641-1653. https://doi.org/10.1016/j.scitotenv.2018.02.300

Open Access This chapter is licensed under the terms of the Creative Commons Attribution 4.0 International License (http://creativecommons.org/licenses/by/4.0/), which permits use, sharing, adaptation, distribution and reproduction in any medium or format, as long as you give appropriate credit to the original author(s) and the source, provide a link to the Creative Commons license and indicate if changes were made.

The images or other third party material in this chapter are included in the chapter's Creative Commons license, unless indicated otherwise in a credit line to the material. If material is not included in the chapter's Creative Commons license and your intended use is not permitted by statutory regulation or exceeds the permitted use, you will need to obtain permission directly from the copyright holder. 